\title{
Understanding The Barriers To Recruiting Women In Engineering And Technology Programs
}

\author{
J. M. Thom, R. E. Thompson, C. Hoy \\ Purdue University
}

\begin{abstract}
Traditional recruiting strategies for engineering and technology seem to be ineffective on modern young women. The traditional model may allude to the "adventure" or "uniqueness" of the career field. It may emphasize hardware or products. Indications are this traditional way of describing a career may actually be a de-motivator for young women.
\end{abstract}

The traditional recruiting model ignores the internal needs of young women. Women are very conscious of self-image and self-worth in their teen years. At a time when they are coming to grips with these factors, teenage women are bombarded with imagery in the mass media of what is considered successful. For example, television programs depicting successful women show lawyers or doctors, not engineers or technologists. The mass media plays a role as a de-motivator by reinforcing stereotypes and supplying inaccurate role models. This same stereotyping and prejudice exists in the high schools, possibly as a result of media influences on educators.

Young women are strongly peer influenced. This leads to the perception by young women that by entering technical career fields they are going to be perceived as less feminine. Despite years of gender equity efforts, young women are convinced that males have more inherent technical knowledge than females. Interviews with students find many women assume men have superior technical knowledge. This assumption coupled with young women's self-image issues, makes them afraid of appearing inferior before a peer group.

Our research suggests it is critical to address young women's internal barriers. The normal anxieties encountered by teenage women are not independent of career development issues. These normal anxieties are the foundation of efforts needed to bring more women into engineering and technology. Unless these issues are understood and proper recruiting strategies developed, none of the exterior efforts, such as Equal Employment Opportunity (EEO) or aggressive recruiting, can have sustainable affects.

\section{Introduction}

Universities and industry continue to have difficulties in recruiting women into technically based professional careers. Despite forty years of gender equity advances and aggressive attempts by both academia and industry to interest women in these areas, women are still not choosing some of the very technical career fields in large numbers. Various reasons for this disparity have been proposed over the years and many of the limiting factors have already been addressed. Through aggressive human resource initiatives and a new management mentality, acceptance of women in 
the workplace is substantially improved. Gender inequities in the teaching of math and sciences at the high schools have been recognized as a factor. That factor has been addressed nationally in recent years. At the dawn of the new century, what appears to remain as a barrier to the entry of many women into technical career fields is an inherent lack of initial interest in these fields from the women themselves. Empirical evidence and direct interviews with many young women reveals a distinct disinterest in entering many engineering and technical disciplines, despite exceptional career opportunities existing in those careers. Direct interviews with numerous undergraduate women over an eight year time span as revealed a distinct and common set of stereotypes and self image issues which seems related to these women's career choices. Pilot studies and questionnaires to groups of undergraduate women also reveals the presence and influence of the decisions made based on stereotypes, but they do not seem to get to the basis for the stereotypes perceptions of careers.

If the academic and industrial climate is currently so receptive for women in these areas, yet young women actively choose not to pursue them, then this would be indicative of some other factor remaining to be addressed. Through empirical evidence and interviews with young women conducted in one program at Purdue University, evidence has begun surfacing indicating the traditional efforts towards recruiting women into technical professional careers does not reflect the needs of the individual women. Rather, the effort toward recruiting is based on a traditional male perspective, and does not address the unique and important issues to young women. Additionally, inputs from women interviewed indicates some counter productiveness by many of the targeted efforts toward women.

\section{The traditional approach}

When attempting to interest young men in careers, there is a model that seems to be the standard used by academia, industry, and the military. In this model concepts are addressed which appeal to young males. Emphasis may be placed on hardware such as jet airplanes, fast cars, big engines, more gigabytes, etc. Males often identify well with "the toys" of a particular industry. Another area of emphasis may be on the adventure aspect of a job. In fact, most branches of the United States military have used this in successful recruiting campaigns. This particular motivator has been long recognized as a contributor to many anti-social choices by young males. Whether simply acting out a juvenile prank or participating in a gang activity, the adventure aspect seems to draw the males very strongly. Honor, also seems to motivate males. In fact, the United States Military has again successfully used this as a traditional motivator for both recruiting and training for many years. While these motivators are not exclusive to males, they do in general appear to be stronger motivators for males than females.

This traditional approach to recruiting makes the assumption that young men and young women are the same, and are most strongly motivated by the same factors. This philosophy of having no difference in recruiting motivations reflects much of the philosophy of the Industrial Psychology work of the 1970's. ${ }^{1}$ Most of the Industrial Psychology research done with regard to human resource management in job selection and job evaluation, stressed gender equivalency as a main issue. That human resource work very strongly discouraged any dissimilar evaluation of males and females. Most of the studies of job performance through that time frame did 
indeed indicate no differences in potential job performance based on gender, and so the modern Human Resources philosophy resulting from that extensive body of work has stressed the minimization of gender differences in the workplace. In academia similar philosophies of promoting gender equity have evolved using the same research data and have identified no significant differences in performance by gender.

While this research, and the application of its findings, has gone a long way toward improving the career options for women, it has not addressed the fundamental issues of why women would want to select a particular career option and what satisfies them in that career. While that issue may be different from one career choice to another, there is some current empirical evidence in the technical career fields indicating young women make career choices for reasons other the ones used by men. It also indicates that they are not making choices based on the types of information presented by career advisors and professional educators. There are indications the young women have much different primary motivators than what young men have and that these motivators may be significantly different than what they were thirty years ago at the beginning of the serious efforts toward encouraging women in professional careers. These motivators work to both encourage and discourage young women from a career choice. ${ }^{2}$

\section{Different motivating factors}

As evidence in the differences in motivating factors between men and women, one has to look no further than the professional advertising field. The "Madison Avenue" type advertising agencies have for years capitalized on these differences. The success of the philosophy exists in the results. Each year corporations pay advertisers hundreds of millions of dollars to sell products based on a proven concept that women are motivated by particular issues. Magazines cater to issues that seem to be of more interest to women than men. Fashion is geared toward the unique interests of women. Products are displayed featuring aspects of interest to women. Entertainment programming is designed to address concepts women find of interest. While some might argue the advertising and entertainment industries may at times exploit these factors and promote them to excess, there can be no doubt that in order for there to be excess or exploitation, there must be some validity to the underlying concepts. It is therefore incumbent on academia and industry to understand these concepts, and to provide women with career guidance in a way that acknowledges these unique motivators. It is necessary in order to best serve young women's needs, that industry and academia deliver their message in a manner directly addressing these motivators.

Direct interviews and pilot surveys with young women in technical careers in aerospace at Purdue University has revealed some interesting motivators regarding why some young women choose a technical career and why some young women do not. In the particular application in aerospace where the interviews and surveys were conducted, the women all were interested in aviation/aerospace careers. Within the same academic department of the same major university, the women had two choices. One choice was to pursue a business administration type major, and the other choice was to pursue a technical type major. Interviews with the young women over several years have revealed some very interesting motivations for their decisions. 
The positive factors the women report on what they want from a career, place "camaraderie" and "self-reliance/independence" as motivators. The women want to enter a workplace where there is a supportive atmosphere and one where there is a community environment. While these factors can exist in a technical career, they are not traditionally stressed during recruiting, and are not often stressed as a human resource management function. While the management philosophy of Total Quality Management and the 14 principles of Deming do call for a positive team philosophy, this management principle is most often directed at technical support between working groups, rather than the daily inter-personal dynamics within a working organization. ${ }^{3}$ The non-technical career fields seem to be perceived as offering more community and interpersonal satisfaction than do the technical fields. Without direct knowledge of exactly what the two different career paths in aerospace involve, the young women are drawing their conclusions from some stereotype they develop from society in general. While these positive motivators describe part of the story, the negative motivators seem to play an even stronger role.

In individual interviews with undergraduate women, and from data gleaned from pilot studies, this sense of community and teamwork is a big draw to the female students toward a career. In the technical program in aerospace where many of these women were studying, they often revealed in personal interviews that one of the things which made them satisfied with their career choice was the atmosphere of teamwork and community which the academic department fostered among its students.

The young women who settled on the non-technical careers often seemed to do so by virtue of the fact that they excluded other options due to negative perceptions about those fields. It is interesting to note that in most cases the reasons they excluded the technical career option are also cited as being the same factors which trouble women who did select the technical career choice. So the factors determining career choice may not be as much that women are drawn toward an area that they enjoy as much as it is that they are eliminating other choices based on perception factors of things they do not like about that alternative choice.

Image and fear of failure are reported in personal interviews and pilot studies as being the strongest factors preventing young women from entering a technical field. They are also the factors cited by young women who did enter into technical career fields as being of serious concern. The women interviewed expressed a strong apprehension about entering a technical field due to the fact they held a strong belief the males held more technical knowledge and competence. This erroneous belief that their male peers held more technical competence led the female students to be afraid of "looking dumb" before their peers. It was not only "looking dumb" before the males causing anxiety for the young women, but they also had a fear of being perceived as appearing "dumb" by other young women.

The second obstacle the young women expressed in these interviews and pilot studies had to do with self-image. How they were perceived in terms of physical appearance played a big role in their career decision process. The women perceived the non-technical aerospace careers as offering the opportunity to maintain a more feminine image than would the technical careers. This apprehension has been expressed repeatedly girls interviewed about aerospace careers. The young women who did enter the technical career field in aviation also expressed this fear of 
being perceived as non-feminine. Exactly why these young women did still enter the technical side of aerospace is not defined, however it is safe to assume they had received mitigating support from some source. Regardless of the fact that one population of the young women did enter the technical side of aerospace, they substantiated the same self-image fears as the other women.

The self-image perceptions by the young women revolved around a loss of feminine appearance and being perceived as not being feminine. This was a fear not only of being perceived as not being feminine or "pretty" by the males, but especially of being perceived as not being feminine by the other women. The desire to maintain feminine appearance and feminine attire was not only to maintain an external image to their peers, but also due to the desire to satisfy their own preference for feminine fashion and appearance. The perception of the loss of femininity has been a recurring theme in interviews with young women regarding technical career choices.

Even after young women enter a career field and realize the males are not more technically competent, there is still the fear of becoming "invisible", or "one of the guys". This success by young women of being accepted as technically competent can lead to the feeling of no longer being perceived as feminine, and can prove to be very difficult for young women to deal with psychologically.

This concept of wishing to maintain a feminine self-image should not be simply dismissed as vanity. The issue at hand is the desire of the young women to maintain their female identity in the industrial social setting. When making career selections they are choosing career paths where they see the ability to maintain their feminine identity and still work as equals in the workplace. Even if a career field is gender neutral in terms of career advancement, the young women are not selecting that career field if it appears to them that as individuals in the industrial social setting they will become overwhelmingly gender neutral. When they do choose these gender neutral career fields it can also lead to anxiety over no longer being perceived socially as distinctly female.

It can be argued as to the source of this perception by young women regarding how this negative stereotype of technical career fields has come to be, and how it is reinforced. It is irrelevant however, at this juncture whether the source of the problem is with the popular media, school education, social pressure, peer pressure, or family pressure. The fact remains that it exists and is not likely to change in the foreseeable future. It is most likely that the reinforcement of the stereotype is coming from a multiple sources and cannot be changed in the short term by any single effort. It is more important to accept what young women believe, whether correct or not, and adjust the recruiting methods to account for it. It is important to recognize that young women wish to be perceived as being female and do not wish to forfeit all of the social amenities that entails. Meanwhile at the same time they wish to be given equal access to all opportunities that are available in the workplace. These are not mutually exclusive paradigms. The blending of these two concepts does however appear to be one for which a set of social rules by which both young men and young women can define their roles with regard to each other there has yet to be developed. This lack of social definition has left both young men and young women with no clear understanding of how they can interact and be perceived in the workplace. 
IV. What needs to be done? Studies.

The information learned from the women interviewed over the past eight years and from the more recent pilot studies needs to be supported by more quantifiable data. To date much of the information gathered has been done so anecdotally, which is by no means scientific. What the anecdotal information has done however has been to indicate to this author that there has been common factors cited by the young women interviewed over this period. The common perceptions cited by these young women have been strong enough to make the author take note and to begin exploring the validity of these common perception indicators through more scientific data collection means.

Pilot studies have lent some support to the empirical data gathered; however developing the correct survey instrument has been the biggest obstacle. Written surveys using typical questions and agree-disagree scales do not seem to be particularly effective in gathering perception data from young women. The young women who have taken such surveys, and the young women who have been working as research assistants on this project, have confirmed that women are noticeably sensitive about being surveyed and investigated. Information gained from they typical multiple choice surveys seemed to prompt the women to adopt a defensive mode of thought or a politically correct mode of thought when answering.

The current effort has gone to gathering data using structured focus groups and by using more open ended survey forms. It is felt that the focus group format provides the women surveyed with the comfort level to answer questions based on their perceptions rather than answering based on correct sounding rhetoric. As of the spring of 2001 several focus groups have been scheduled by a graduate researcher in the Purdue University School of Technology Graduate program. These focus groups are being conducted to study career perceptions and the role of social interaction and courtesy in women's choices to select a highly technical career. From these focus groups information is to be obtained regarding the factors women use when making career choices. It is also to gather data on then kinds of perceptions and stereotypes women have about careers. The focus groups are intended to find what dominant factors or perceptions women are using when making choices.

V. The Factors Expected to Result from the Studies.

Based on the initial pilot studies, focus groups, and individual interviews there are some predictions about what to expect from the larger studies. The enticement into a career area for young women may result from substantially different motivators and barriers than what affect young men. The traditional model used by professional career advisors of what is used to recruit men may actually be a determent to the attraction of women into a discipline. The paradigm used for women must emphasize the positives young women value and must address the negatives young women fear. On the positive side any career presentation must have the emphasis on "camaraderie" and on "self reliance/independence" cited by women. It is further important that academic programs ensure they have an educational and social system supporting that emphasis. 
Most importantly, it is important to recognize the de-motivators, or the image/fear barriers young women create for themselves when viewing technical careers. Industry, academia, and professional societies must actively work to find ways to show the young women that being technically competent does not mean a loss of femininity.

There seems to be very little attention paid up to this point regarding the psychological barriers young women develop for themselves with regard to career choices. Data should indicate that any recruiting or career development program must recognize that young women have these substantially different needs than do their male counterparts. While the traditional recruiting and career development methods should not be discarded since they can be effective when used in the proper context, more attention must be paid to the unique needs of the young women.

The real difficulty then becomes in how to develop a social structure in academia and industry which caters to the unique needs of both women AND men. The students currently interviewed have indicated that while women have unique needs, there is also a very real danger of establishing a climate of overcompensation by organizations in dealing with those needs. Both male and female students have expressed some frustration in the lack of a social norm for society and organizations in the setting of standards of expectations for men and women in the society of the workplace.

One of the most effective career development tools for young women is some kind of visible role model. Young women need to see other women in technical career fields who represent what is possible to achieve. Young women need to see that it is possible to be technical and feminine. Whether by direct contact or by some kind of media stereotype young women need to see that these two concepts are not mutually exclusive. So what is an effective role model? It has long been recognized that children develop career tendencies very early. In the work by Eiff et al ${ }^{4,5}$, it was again determined girls needed inputs regarding career choices at 9 to 12 years old. It was further determined that when the role model was supported by the family, it had the most impact on the career decisions. Based on this and other related research it, becomes important to find a means of allowing the younger girls to integrate the career possibilities into their self identity before or at the same time they come to grips with the other self-identity issues of the teenage years.

While roll modeling has long been recognized as a strong positive influence, the way roll modeling is done may need to be re-examined. Using the traditional role model that exposes girls to the technical aspects of a career, may well not be nearly as important as having a role model who simply provides girls with a compatible feminine identity and appearance in a technical workplace. The issue of the role model may well need to address what the girls needs in terms of identity, more so than just show girls what careers are possible and that there are women in them.

The concept of women's organizations providing role models has produced some interesting responses from the college age women interviewed. Many of the young women belong to, or have been affiliated with, professional groups or organizations primarily devoted to supporting 
women. Interview data indicates that young women do not feel the professional organizations accurately role model and support the needs of the current generation of young women. Some organizations actually reinforce the young women's fears about loosing femininity. Some young women are discouraged by a perception that the organization is focusing heavily on gender based social-political issues. In almost all reports the young women were disappointed when they felt the organization did not address the personal concerns about careers discussed here.

It is also important for organizations wishing to encourage young women to pursue some career field to make sure that the recruiting materials and presentations address the unique needs of the female recruit. Use role models for tours. Take the time to let the role models address the women's issues. If female role models are not available then the institution has to assume that duty. It becomes necessary to format the delivery of the career information and the method of delivery to address the female prospect's needs and fears. Just as important, is to make sure that the support delivered by the recruiting organization is not too overt. An over-emphasis on the women's issues can be just as damaging from the prospect of allowing the female recruits to feel "spotlighted". It can also lead the female recruit to feel that their participation in the academic program, or career field, is desired only as a part of a social-political agenda. The problem for many academic activities is that they do not know how to effectively address the young women's needs.

It may well be that many organizations tend to avoid addressing the unique needs of young women in the interest of some kind of defensive political correctness. It is safer politically to ignore that women are different, have a substantial number of different needs, and a substantial number of different perceptions. To address women's unique needs opens the organization up to being perceived as segregating women or to viewing women as second class people. Conversely organizations aggressively pursuing young women and attempt to address young women's needs, may be perceived by the young women as simply pursuing some kind of social political agenda, i.e. recruiting just to fill the quota. Many of the women undergraduates interviewed over the past have expressed a negative reaction regarding women and organizations who aggressively and politically pursue women's issues. The model then must be developed which can allow organizations to address young women directly and to address their unique personal needs, but at the same time not make women feel the object of a large scale social-political scheme. At the same time the model must address the men's issues of what are the normal differences and expectations of women. By helping the men to understand the business social model, the climate of acceptance of women can be greatly enhanced. Without this effort aimed at helping the men to know where to fit in the picture. The current model that men are given is to ignore all differences between men and women. Given the common sense factor in people men recognize that is not a valid business premise, but have no guidance for what expectations to have. The result is some form of social conflict in the organization.

\section{Conclusions}

At this point it would appear that people in a position to influence young women on technical career choices are not addressing the basic needs of the young women. A lack of understanding of young women's individual needs and a fear of social rebuke for making such an 
acknowledgment drives many organizations to adopt the philosophy of ignoring the fact that there are any differences. A fear of backlash from both men and women when too much effort is placed on the issue also drives many organizations way from the acknowledgment of differences.

On the larger scale it is apparent that young women will continue to discourage themselves from technical careers as long a popular media stereotypes continue to portray engineering and technology as un-feminine and not social in nature. Until entertainment outlets such as girls magazines and television overcome their own stereotypes about the appearance of women in technical careers, more generations of young women will most likely be discouraged from entering rewarding career fields. Until educators in the primary and secondary education ranks overcome their negative stereotypes, young women will continue to receive discouraging signals regarding technical careers.

Businesses and higher education institutions can play some role in helping young women to develop positive perceptions about technical careers. The can only be done when the issues relevant to modern young women is known and the key factors are acknowledged. Once done effective recruiting strategies can be employed which cater to the important, unique perceptual needs of the young women.

It is hoped that the current round of focus group studies and survey studies reveal what is important to the young women of the new century. These issues are anticipated to be items relevant at the individual level, rather than being broadly sweeping social issue. As such the continued effort to attract young women into technical careers may have to shift from the broad national political arena, and into the arena of addressing the needs of the women at the personal level.

At this point, there are no quick solutions proposed for this problem. Strong career motivators and de-motivators have been identified among the young women entering or contemplating technical fields. ${ }^{6}$ To date, that information has been gleaned from direct interviews. Currently, young women are acutely aware that they are the target of extensive consumer and social research. The result of this awareness is a tendency to "play the game" and to provide the researcher with data the women feel the research wants. The challenge at this point is to find a survey instrument accurately correlating with the direct interview data. It is most likely that structured data from direct interviews and some focus groups is the only way to provide the statistical support for the empirical data obtained so far. Once this data can be obtained in a statistically defensible manner, then we can better address the underlying emotional underpinnings affecting young women's career decisions.

It is necessary to accept the fact that young men and young women use different priorities when assessing career choices. This acceptance should not reflect a condemnation of either method, nor should it be construed as a statement that either method is inferior to the other. It is simply an acceptance of the different psychological needs of each group. 
Before large-scale actions can be taken, the basic motivations of the young women in career selections must be understood. Young women have different fears and motivators than do young men. These factors must be understood and accommodated, not because the young women are in any way inferior, but rather because their needs are different and unique. To ignore the unique emotional workings of pre-teenage and teenage girls does nothing toward providing constructive career guidance. Young women have demonstrated a rejection of total gender neutrality as structured by the human resource models in industry, and have instead adopted a strategy of finding career fields which allow them to maintain a feminine identity, yet still have equal career opportunity.

The advertising media and the entertainment media have fully embraced this concept successfully. While it may not be practical or desirable to cater to women the way these industries do, it must be recognized that they have been successful based on understanding what is important to women. These media understand the paradigm that women place a value on femininity and self-image. They also understand many of the fears that women have and direct the message towards those fears. Women are interested in careers allowing them to be feminine and professional. It is therefore incumbent on industry and academia to market the career fields addressing those needs.

Bibliography

1. Gatewood, R. D. \& Field, H. S. (1987). Human Resource Selection. Dryden Press.

2. Orr, J. P. (1983) . Factors Influencing Participation of Females in the Industrial Technology Program at Southern Illinois University-Carbondale. Unpublished doctoral dissertation, Southern Illinois UniversityCarbondale.

3. Evans, J. \& Lindsay, W. (1999). The Management and Control of Quality ( ${ }^{\text {th }}$ ed.). South-Western College Publishing.

4. Eiff, G. M. (1989). The Impact of an Experimental Aviation Career Orientation Workshop on the Career Interests and Aspirations of High School Girls. Unpublished doctoral dissertation, Southern Illinois UniversityCarbondale.

5. Eiff, G. M., Eisman, T. K., Stahura, J. \& Stitt, B. A. (1993). Recruitment Selection, Training and Placement of Non-Traditional Workers in Aviation Maintenance. Available from Aviation Education Consultants, 761N 400W, West Lafayette, IN 47906)

6. Thom, J. M. (2000). [Survey analysis findings and empirical data summary]. Unpublished raw data.

\section{J. MARK THOM}

Mark Thom is currently an Associate Professor in the School of Technology at Purdue University. He received his B.S. from Purdue University in 1981 in Aviation Technology and was employed in aerospace engineering flight test for eleven years. He received his M.A. in Industrial Psychology from the University of Missouri in 1989 and came to Purdue in 1992.

\section{RAYMOND E. THOMPSON}

Raymond E. Thompson is Associate Professor of Aviation Technology at Purdue University in West Lafayette. Prof. Thompson founded the AOT Advanced Composite Laboratory and coordinates student services within the department. His current research includes assessment, technology in the classroom, distance education, and aviation human factors 


\section{CAROLYN HOY}

Carolyn Hoy is a junior in the School of Technology at Purdue University. She has been actively involved regarding the recruiting of high school girls into aviation and aerospace careers. She has presented on this subject before industrial committees and gives career presentations to high school and pre-high school girls. 